\title{
The Stars and the Sky at the EPS
}

\section{E. Schatzman}

\section{History}

Astronomers in Europe are organized in different national societies which, however, do not exist in every country. After 1968 the idea of forming a European society began to spread and the desirability of tightening the links between astronomers and physicists came to be recognized, astronomy offering a wide field of application for the physicist, and the astronomer needing more and more physics in his work.

In April 1969 at the EPS Inaugural Conference in Florence, which proved very successful for astronomy thanks to a special session on astrophysics and general talks on pulsars and cosmology, the question was raised whether to create a European Astronomical Society or an EPS Division in this field. At the Cortona meeting on weak interactions in astrophysics in June 1970 it was decided to aim towards the creation of an EPS Division to tighten links between physicists and astronomers. In August 1970 at the Brighton conference of the IAU it was agreed to petition the EPS Council accordingly and to form an interim Steering Committee to organize the new division from the following scientists :

\section{E. Amaldi, Rome}

L.A. Artsimovich, Moscow

R.H. Bernas, Orsay

H. Bondi, ESRO

G. Charpak, CERN

G. Cocconi, CERN

F. de Felice, Padua

T. de Graaf, IOTA and Groeningen

J. Friedel, Paris

M. Hack, Trieste

G. Marx, Budapest

L.A. Radicati, Pisa

M.J. Rees, Cambridge (Secretary)

E. Schatzman, Paris (Chairman)

D.W. Sciama, Cambridge

The EPS Council in Budapest, October 1970, accepted the new Division leaving the choice of name to the Steering Committee.

\section{General Principles}

Better relations between astronomy and other fields of physics are of paramount importance. Progress in astronomy and astrophysics is closely related to advances in physics which, in turn, are increasingly stimulated by the latest discoveries in astrophysics and by the possibilities of astronomical experimentation (space probes).

\section{Functions of the Division}

1. To establish contacts between institutes and individuals working in astronomy and related fields, by encouraging cooperation between astronomers and physicists, by the exchange of scientists (summer visitors), students and publications, the collaboration on research projects and the creation of European institutes. To improve contacts between individuals and laboratories active in fields related to the properties of astronomical objects, ranging from gravitation to high energy physics. To promote cooperation in education and to establish links between the IAU and the EPS.

2. The organization of meetings on specialized subjects together with other EPS Divisions. Such meetings must be held at European level because specialists in each field are few in the various countries. The organization of summerschools and special sessions at EPS General Conferences.

3. As regards information policy, the Division should encourage cooperation in the publication of literature, assist in its compilation and prepare reference lists of institutes and individuals.

\section{First Decisions}

At the Brighton meeting it was suggested that the rules and regulations should be drafted within one year from the constitution of the Division and that the first board of the Division should be approved by the first divisional meeting. The importance of the participation of young EPS members in the new Division was stressed; as the most active in the field they, above all, should benefit from the advantages of a European organization. This new Division will be

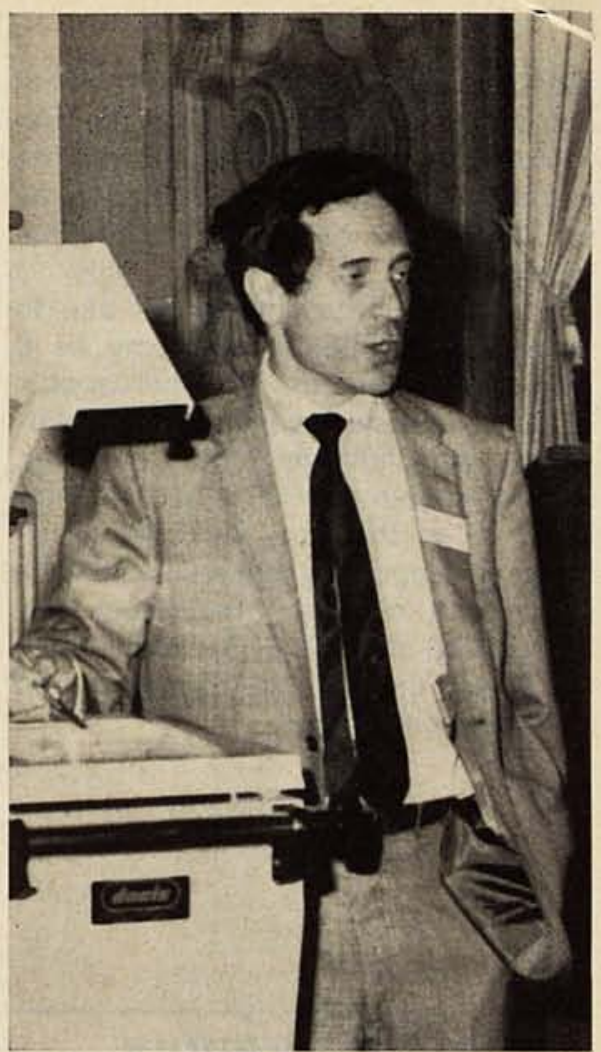

successful only if young people are elected to the board.

As a first step interested scientists will be informed and prospective members will be invited to join the EPS. The first meeting of Division members is to be held in autumn 1971 at a place yet to be decided.

\section{Name of the Division}

Although the term astronomy covers astrophysics, astronomers and astrophysicists nowadays are concerned with different aspects of the physics of celestial bodies. To call it the Astrophysics Division would make many feel excluded from membership, whereas 'Astronomy Division' would encourage all astronomers who value the links between physics and astronomy to join the EPS. The incorporation into a physical society will strengthen such links and clearly indicate that the Division's interests go beyond the traditional ones. Although all branches of astronomy are to be served, the association with physicists will be most valuable in borderline subjects, such as space physics, cosmic ray research and $X-$ ray astronomy. To use the existing administrative structure will be more economical than setting up a completely separate organization. As scientific academies of both Eastern and Western Europe adhere to the EPS, better contacts between astronomers from East and West can be established.

At the Budapest meeting the EPS Council expressed a preference for the name 'Physics in Astronomy' for 
the Division, at least on a provisional basis, as it would promote the development of further relations with the astronomical community. This name will, therefore, be used for the time being.

The new Division does not aim to represent European astronomy as a whole but rather the physics aspects of astronomical sciences. All interested astronomers are, however, invited to join the EPS and its new Division, so that, one day, the possibility envisaged by several scientists inside and outside the Society may be realized and the EPS may become the EPAS, the European Physical and Astronomical Society.

\section{Bernard P. Gregory leaves CERN}

On the occasion of his completion of five years as Director-General of CERN, Europhysics News takes this opportunity of expressing its appreciation of the help and encouragement the Society has always received from B.P. Gregory. CERN is one of the outstanding examples of European collaboration and under his leadership it has had an important influence on the creation of the EPS and the establishment of its infrastructure. So positive is the drive towards internationalism in the high energy physics field and so firmly is CERN established as a centre for both research and communication for particle physicists everywhere, that it was natural to look towards CERN in order to profit from the experience available there and the personal guidance of its Director General.

The Society was founded at CERN on 26 September 1968 at a ceremony presided over by B.P. Gregory and CERN has been involved in the organization of the Florence conference and in the founding and publishing of Europhysics News. From the beginning B.P. Gregory was a member of the Steering Committee for the formation of the EPS and CERN was the first Associate Member of the Society.

Bernard Gregory returns to the Ecole Polytechnique in Paris from where his personal influence will continue to be felt in the promotion of European ideals in the world of physics. The new Director-General of CERN as reported in Europhysics News of July 1970 is W.K. Jentschke.

\section{Society News}

\section{Individual Ordinary Members}

We are pleased to announce that, with the list of acceptances published opposite, our Individual Ordinary Membership now exceeds 1500 . This gratifying response to the appeals for support of the EPS will, we trust, continue in the new year and, by this growth, help to strengthen the Society.

\section{Member Societies}

P. Urban, Graz, has been elected President of the Austrian Physical Society replacing K. Lintner, Vienna.

N.I. Meyer, Lyngby, is President of the Danish Society for Physics and Chemistry of Condensed Matter until 1 December 1971, and A.R. Mackintosh will represent it on the Council.

J. Aguilar, Madrid, has been elected President of the Spanish Royal Society of Physics and Chemistry, for the period 1970 to 1972.

J. Gomes Ferreira, Lisbon, is the delegate to the EPS Council from the Portuguese Physics and Chemistry Society.

Members of the EPS and of national societies associated with the EPS wishing to attend conferences organized by the German Physical Society (DPG) will benefit by the concession of the 'DPG Members' rate for the conference fee.

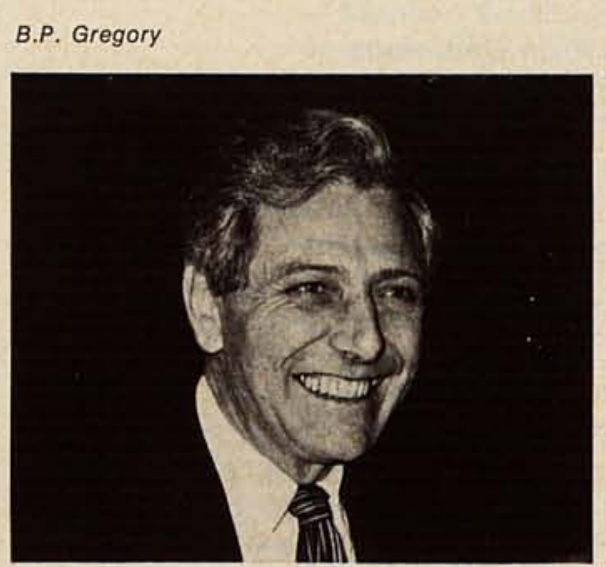

\section{Associate Members}

The following organizations have decided to join the European Physical Society as Associate Members :

Brown, Boveri \& Company Ltd., Baden, Switzerland

IBM Research Laboratory Zurich,

Rüschlikon, Switzerland

Masson \& Cie, Paris, France

\section{Sponsors}

Members of the German Physical Society have donated DM 3785 following the appeal by K. Ganzhorn, President (see Europhysics News No. 11).

The Israel Academy of Sciences is donating US $\$ 1000$ as a national contribution to the EPS.

We also gratefully acknowledge the receipt of small donations totalling Sw. fr. 500.- from several Individual Ordinary Members of EPS.

\section{Divisions}

The Board of the High Energy and Particle Physics Division is organizing its first specialized conference to take place in Bologna from 14-16 April 1971. The general topic will be meson resonances and related electromagnetic phenomena, a field in which development is at present very rapid. Attendance will be limited to two hundred participants, preferably physicists actively engaged or greatly interested in this domain.

\section{Europhysics News}

With the present issue, Europhysics News starts its second volume and plans are being made to increase its rate of publication to ten issues per year including the two Meetings Issues once a part-time editor has been recruited.

Volume 1 comprises the Special Issue of November 1968, Nos. 1 to 12 from January 1969 to November 1970, and Meetings Issues 1 and 2 (12M) of 1970. An index for Volume 1 is included in this issue. 